\title{
Optimal timing of the Fontan conversion: Change in the P-wave characteristics precedes the onset of atrial tachyarrhythmias in patients with atriopulmonary connection
}

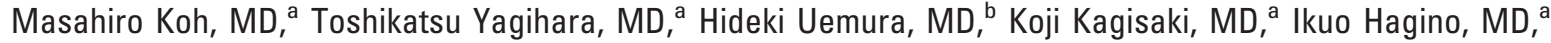 \\ Toru Ishizaka, MD, ${ }^{a}$ and Soichiro Kitamura, MD ${ }^{a}$
}

From the Department of Cardiovascular Surgery, the National Cardiovascular Center, Osaka, Japan ${ }^{\mathrm{a}}$; and the Department of Cardiothoracic Surgery, Royal Brompton Hospital, London, United Kingdom. ${ }^{\mathrm{b}}$

Read at the Eighty-sixth Annual Meeting of The American Association for Thoracic Surgery, Philadelphia, Pa, April 29-May 3, 2006.

Received for publication April 27, 2006; revisions received Dec 1, 2006; accepted for publication Dec 18, 2006.

Address for reprints: Toshikatsu Yagihara, MD, Department of Cardiovascular Surgery, National Cardiovascular Center, 5-7-1 Fujishiro-dai, Suita, Osaka, 565-8565, Japan (E-mail: yagihara@hsp.ncvc.go.jp).

J Thorac Cardiovasc Surg 2007;133:1295-302 0022-5223/\$32.00

Copyright () 2007 by The American Association for Thoracic Surgery

doi:10.1016/j.jtcvs.2006.12.008
Objectives: Atrial tachyarrhythmia is a common complication late after the atriopulmonary connection Fontan procedure. The P-wave duration and dispersion have been regarded as useful markers for its prediction. The purpose of this study was to analyze change in the P-wave characteristics over time after the atriopulmonary connection Fontan procedure, with a special emphasis on the timing of the Fontan conversion.

Methods: We reviewed clinical and electrocardiographic data in 18 patients with classic tricuspid atresia who underwent the atriopulmonary connection Fontan procedure. Their median age at operation was 4.1 years (range, 1.1-22 years), and the median follow-up period was 18.1 years (range, 10-25 years). We measured the P-wave duration, dispersion, and axis from consecutive 12-lead electrocardiograms in each patient.

Results: There was a significant increase in the maximum P-wave duration as well as the P-wave dispersion over time. Transient ectopic atrial rhythm was observed in 16 patients during follow-up. Atrial tachyarrhythmia developed subsequent to transient ectopic atrial rhythm in 8 patients. Ten patients underwent the conversion. Atrial tachyarrhythmia recurred in 2 patients who had sustained arrhythmia (6.0 and 8.0 years) before the conversion. In contrast, the other 8 patients with transient ectopic atrial rhythm alone or nonsustained atrial tachyarrhythmia have been free from arrhythmia after the conversion.

Conclusions: Patients commonly and increasingly had prolonged P-wave duration, larger P-wave dispersion, and ectopic atrial rhythm, along with an atrial tachyarrhythmia propensity, late after the atriopulmonary connection Fontan procedure. These P-wave characteristics were informative when considering the Fontan conversion before a sustained atrial tachyarrhythmia ensued.

A trial tachyarrhythmia is a widely known late complication in patients who have undergone the classic atriopulmonary connection (APC) Fontan procedure ${ }^{1-11}$ and this complication contributes to mortality after the Fontan procedure. ${ }^{1-3}$ Its incidence increases postoperatively with time. ${ }^{3-9}$ The ever-growing population of patients who have undergone Fontan procedures surviving into adulthood is highly susceptible to this complication. Conversion to total cavopulmonary connection in association with antiarrhythmic surgery is a viable option; however, its optimal timing remains controversial. ${ }^{12-20}$

Structural remodeling resulting from complex atrial scars and abnormal atrial wall stress is universal in this setting and leads to atrial electric re-entry ${ }^{4-6,11,14}$ and sinus nodal dysfunction. ${ }^{2,5,21,22}$ The P-wave characteristics have been found to 


\section{Abbreviations and Acronyms \\ $\mathrm{APC}=$ atriopulmonary connection \\ ECG $=$ electrocardiogram(graphic) \\ IART $=$ intra-atrial re-entrant tachycardia}

reflect such structural remodeling of the atrium. In recent reports, two simple electrocardiographic (ECG) markers, namely the $\mathrm{P}$-wave duration and the $\mathrm{P}$-wave dispersion, were studied for the detection of these conduction abnormalities. ${ }^{23-34}$

We conducted a consecutive review of the P-wave characteristics in patients who have undergone the APC Fontan procedure to clarify whether this simple ECG analysis could represent the process of developing rhythm disturbance and could provide useful information to time the conversion procedure.

\section{Patients and Methods Study Population}

A primary enrollment criterion of this study was classic tricuspid atresia and its close relatives. To homogenize the underlying morphologic background, we excluded all other types of malformations, such as heterotaxy, situs inversus, and mitral atresia. In addition, patients with less than 3 years of follow-up were also excluded. Between 1979 and 1991, a total of 60 patients underwent the APC Fontan procedure at the National Cardiovascular Center. Thirty-two of them had tricuspid atresia or severe tricuspid stenosis in the setting of situs solitus. Twenty-seven survived and were discharged, and 6 of these survivors died late (within 38 months after the operation). Three patients were lost to follow-up. This accordingly left 18 patients for review of clinical and ECG data. The institutional review board approved this retrospective chart review, and individual consent was waived.

The study population consisted of 9 male and 9 female patients. Fifteen patients had tricuspid atresia and 3 had severe tricuspid stenosis. Ventriculoarterial connections were concordant in 14 , double-outlet from the incomplete morphologically right ventricle in 3, and discordant in 1 patient (Tables 1A and 1B). Fourteen patients had a previous palliative procedure, including systemicpulmonary artery shunt in 12 , the Glenn shunt in 1, and enlargement of the intra-atrial communication in 1. All patients were in sinus rhythm before any surgical procedure. Originally, they underwent the APC Fontan procedure; the Fontan circulation had been established by direct anastomosis between the pulmonary artery and the right atrial appendage and closure of intra-atrial communication by direct suture or patch technique. The median age at the initial Fontan procedure was 4.1 years (range, 1-22 years). Yearly follow-up was complete in all except 2 patients; one dropped out from the routine follow-up 10 years after the initial Fontan procedure (patient 8 ), and the other had less frequent follow-up until acute thromboembolism of the pulmonary artery developed (patient 18). The median follow-up period was 18.1 years (range, 10-25 years).

\section{Analysis of ECG Markers}

Consecutive 12-lead surface ECGs in all 18 patients were examined from the early preoperative period to the latest follow-up. The majority of the ECGs were recorded at the outpatient clinic as part of a routine screening examination. Those ECGs in which $\mathrm{P}$ waves could not be identified owing to atrial tachyarrhythmia or those recorded after the conversion procedure were excluded from the $\mathrm{P}$-wave analysis. The number of ECGs included in this analysis for each patient ranged from 6 to 37 .

The ECGs were recorded at a paper speed of $25 \mathrm{~mm} / \mathrm{s}$ and $1 \mathrm{mV} / \mathrm{cm}$ standardization. We measured the P-wave duration and amplitude in all 12 leads recorded simultaneously. A single investigator, blinded to the patient's name or sequence of the ECG, performed all measurements. Measurements were obtained manually from the printout with an electronic caliper (M\&T DC-150P; Mitutoyo, Kawasaki, Japan) and the aid of a magnifying glass (3.7-fold magnification) to confirm reproducibility. The onset of the $\mathrm{P}$ wave was defined as the junction between the isoelectric line and the beginning of the P-wave deflection, and the offset was defined as the junction between the end of the P-wave deflection and the isoelectric line. The P-wave duration was defined as the interval between the earliest onset and the latest offset. The maximum and minimum $\mathrm{P}$-wave durations based on measurements in all 12 ECG leads were calculated, and the P-wave dispersion was defined as the difference between the maximum and the minimum P-wave duration of individual ECG (Figure 1). ${ }^{24-34}$ The $\mathrm{P}$-wave axis in the frontal plane was determined from the P-wave amplitude in the limb leads and the ectopic atrial rhythm was designated as a persistent shift in the $\mathrm{P}$-wave axis greater than $45^{\circ}$ as compared with the preoperative ECG. ${ }^{21}$ The time to ectopic atrial rhythm was defined as the time to the first episode documented by the standard ECG beyond the immediate postoperative period. Atrial tachyarrhythmia was defined as a documented intraatrial re-entrant tachycardia (IART) or atrial fibrillation. Atrial flutter was included under the IART heading.

\section{Data Analysis}

Data are presented as the mean \pm 1 standard deviation. The cumulative event-free rate was estimated by the Kaplan-Meier method. Changes of ECG markers were analyzed with the general linear mixed model with years as a fixed effect and patients as a random effect. The covariance structure was autoregressive. Time was truncated by a year and the latest value in a year was used. $P$ value was calculated by $F$ statistic. All statistical tests were conducted with SAS Statistical Software version 8.02 (SAS Institute Inc, Cary, NC).

\section{Results \\ ECG Markers and Arrhythmia}

There was a significant increase in the maximum P-wave duration over time after the APC Fontan procedure. Similarly, the P-wave dispersion showed a significant increase over time (Figure 2). The mean value of the preoperative maximum P-wave duration was $116.6 \pm 12.6 \mathrm{~ms}$. The mean maximum $\mathrm{P}$-wave duration calculated from the available data extracted in each patient during 8 to 12 years and 18 to 23 years postoperatively was $144.8 \pm 23.4 \mathrm{~ms}(\mathrm{n}=16)$ and 
TABLE 1A. Clinical characteristics of the 8 patients who had not undergone the conversion procedure

\begin{tabular}{cccccc}
\hline Patient No. & Diagnosis & Age at Fontan $(\mathbf{y})$ & Interval to EAR $(\mathbf{y})$ & Interval to AT (y) & Rhythm outcome \\
\hline 1 & TA, DORV & 5.0 & 8.7 & 13.4 & IART, catheter ablation \\
2 & TA, VAC & 2.2 & 10.6 & - No arrhythmia & No arrhythmia \\
3 & TA, VAC & 4.6 & 13.8 & - & No arrhythmia \\
4 & TA, VAC & 3.0 & 11.9 & - & No arrhythmia \\
5 & TA, VAC & 3.2 & 9.2 & - & No arrhythmia \\
6 & TA, VAC & 3.0 & 1.1 & - & No arrhythmia \\
7 & TA, VAC & 4.9 & 8.7 & - & No arrhythmia
\end{tabular}

$T A$, Tricuspid atresia; $T S$, severe tricuspid stenosis; $V A C$, ventriculoarterial concordance; $V A D$, ventriculoarterial discordance; $D O R V$, double-outlet right ventricle, $E A R$, ectopic atrial rhythm; $A T$, atrial tachyarrhythmia; $A F$, atrial fibrillation; IART, intra-atrial reentrant tachycardia; $S A S$, subaortic stenosis; $A V V R$, atrioventricular valvular regurgitation; $P M I$, pacemaker implantation.

TABLE 1B. Clinical characteristics of the 10 patients who underwent the conversion

\begin{tabular}{|c|c|c|c|c|c|c|c|c|}
\hline $\begin{array}{l}\text { Patient } \\
\text { No. } \\
\end{array}$ & Diagnosis & $\begin{array}{c}\text { Age at } \\
\text { Fontan (y) }\end{array}$ & $\begin{array}{c}\text { Interval to } \\
\text { EAR }(y)\end{array}$ & $\begin{array}{c}\text { Interval to } \\
\text { AT (y) }\end{array}$ & $\begin{array}{c}\text { Interval to } \\
\text { conversion (y) }\end{array}$ & $\begin{array}{c}\text { Age at } \\
\text { conversion (y) }\end{array}$ & Indications for conversion & Rhythm outcome \\
\hline 9 & TA, VAC & 2.6 & 6.9 & 9.8 & 15.8 & 18.5 & $A F$, thrombus & AF recurred \\
\hline 10 & TA, VAC & 8.6 & 9.5 & 11.0 & 19.0 & 27.6 & $A F$, thrombus & AF recurred, PMI \\
\hline 11 & TA, VAC & 3.4 & 10.3 & 11.4 & 11.6 & 15.0 & $\mathrm{AF}$ & Transient IART, PMI \\
\hline 12 & TA, DORV & 22.7 & 0.6 & 8.3 & 10.3 & 33.0 & IART, SAS & $\begin{array}{l}\text { No arrhythmia, no } \\
\text { antiarrhythmic drug }\end{array}$ \\
\hline 13 & TA, VAC & 3.3 & 6.6 & 17.5 & 17.8 & 21.2 & IART & $\begin{array}{l}\text { No arrhythmia, no } \\
\text { antiarrhythmic drug }\end{array}$ \\
\hline 14 & TS, VAC & 5.2 & 7.9 & - & 16.0 & 21.2 & $\begin{array}{l}\text { IART (exercise induced), } \\
\text { left-sided AVVR }\end{array}$ & $\begin{array}{l}\text { No arrhythmia, no } \\
\text { antiarrhythmic drug }\end{array}$ \\
\hline 15 & TA, VAD & 5.0 & 12.1 & - & 14.6 & 19.6 & IART (exercise induced) & $\begin{array}{l}\text { No arrhythmia, no } \\
\text { antiarrhythmic drug }\end{array}$ \\
\hline 16 & TA, VAC & 1.1 & 8.3 & - & 15.6 & 16.7 & Poor exercise tolerance & $\begin{array}{l}\text { No arrhythmia, no } \\
\text { antiarrhythmic drug }\end{array}$ \\
\hline 17 & TA, VAC & 3.6 & 3.2 & - & 14.2 & 17.8 & Thrombus & $\begin{array}{l}\text { No arrhythmia, no } \\
\text { antiarrhythmic drug }\end{array}$ \\
\hline 18 & TS, DORV & 9.2 & - & - & 19.5 & 28.7 & Thrombus & $\begin{array}{l}\text { No arrhythmia, no } \\
\text { antiarrhythmic drug }\end{array}$ \\
\hline
\end{tabular}

Maximum

P-wave duration

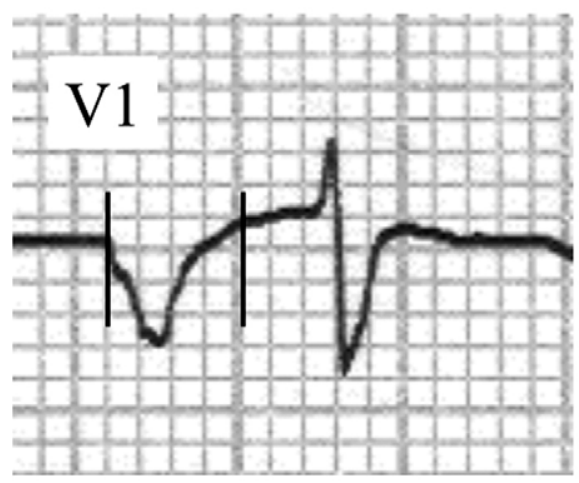

$160 \mathrm{~ms}$
Minimum

P-wave duration

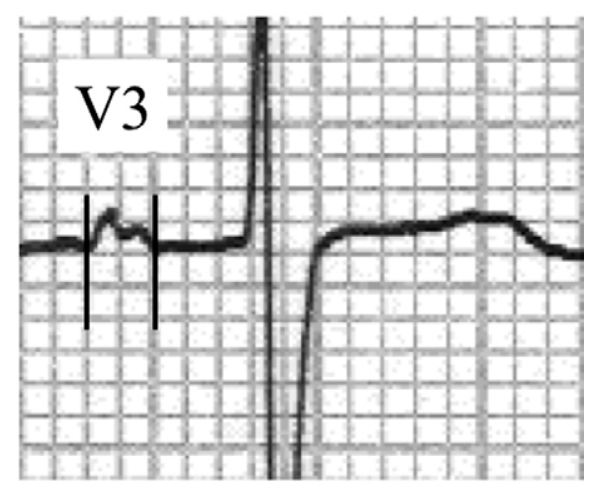

$68 \mathrm{~ms}$
Figure 1. Measurement of the P-wave duration. In this electrocardiogram, the maximum $\mathbf{P}$-wave duration was observed in lead $V_{1}$ and the minimum $P$-wave duration in lead $V_{3}$. The $P$ wave dispersion was defined as the difference between the maximum and the minimum P-wave duration. Therefore, the P-wave dispersion was calculated as $92 \mathrm{~ms}$. 


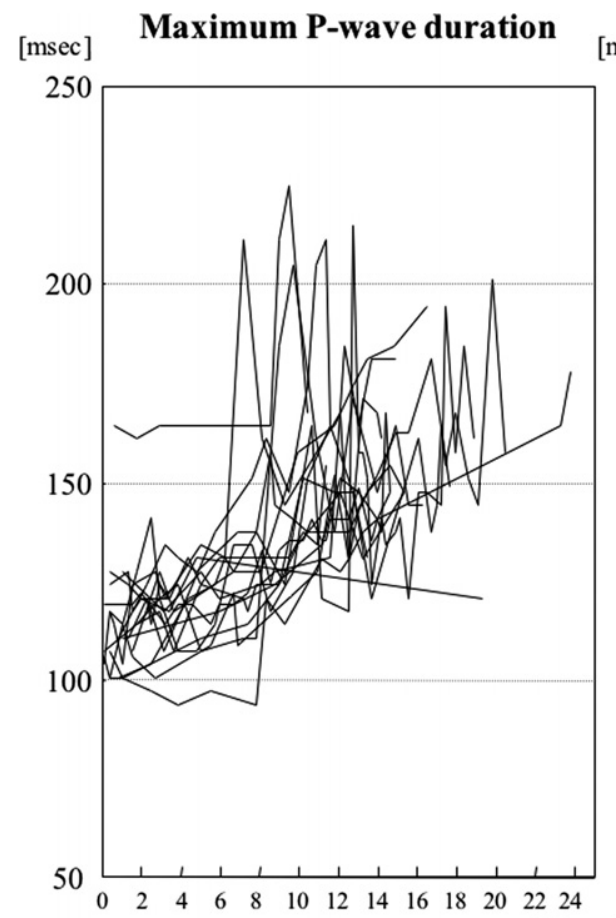

\section{[msec] P-wave dispersion}

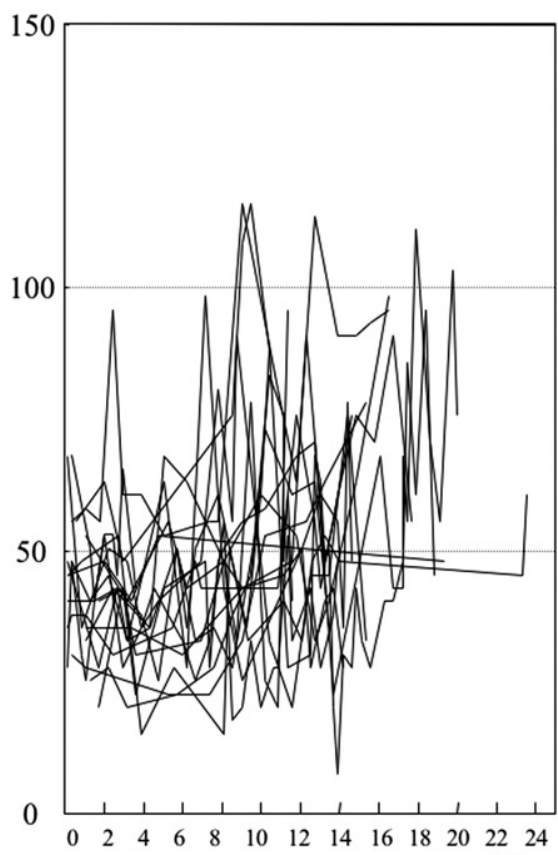

Figure 2. Changes of maximum P-wave duration and $\mathbf{P}$-wave dispersion after the initial Fontan procedure. Changes were analyzed with the general linear mixed model with years as a fixed effect and patients as a random effect. There was a significant increase in both the maximum $\mathbf{P}$-wave duration and the $\mathbf{P}$-wave dispersion. (P-wave duration; $113.2+$ 2.6x $[\mathrm{P}<.001, \mathrm{~F}=59.56, \mathrm{NDF}=1$, $D D F=194]$, P-wave dispersion; $39.5+$ 1.3x $[\mathrm{P}<.001, \mathrm{~F}=15.63, \mathrm{NDF}=1$, $D D F=194], x ;$ year). NDF, numerator degrees of freedom; $D D F$, denominator degrees of freedom.
$161.7 \pm 31.9 \mathrm{~ms}(\mathrm{n}=6)$, respectively. The mean value of the P-wave dispersion calculated in a similar manner was $43.1 \pm 11.4 \mathrm{~ms}$ preoperatively, $55.0 \pm 30.6 \mathrm{~ms}$ during 8 to 12 years, and $70.0 \pm 24.4 \mathrm{~ms}$ during 18 to 23 years.

Ectopic atrial rhythm was noticed in 16 patients during follow-up (Figures 3 and 4 and Tables $1 A$ and $1 B$ ). All of these patients were free of symptoms at the time of ectopic atrial rhythm and remained unaware of such a change. The remaining 2 patients without ectopic atrial rhythm had infrequent ECG data (patients 8 and 18). Survival free from ectopic atrial rhythm was $83.8 \% \pm$ $8.8 \%$ at 5 years, $38.9 \% \pm 11.5 \%$ at 10 years, and $6.5 \% \pm$ $6.2 \%$ at 15 years (Figure 5).

Atrial tachyarrhythmia developed in 8 patients, occurring after a certain period of transient ectopic atrial rhythm in each patient. Eventually, atrial fibrillation developed in 3, symptomatic IART in 3, and exercise-induced IART in 2 patients. Two patients (patients 9 and 10) had persistent atrial fibrillation despite multiple antiarrhythmic medications. They had also right atrial thrombus formation, despite being treated with anticoagulation. Seven of these 8 with atrial arrhythmia underwent the conversion procedure. The remaining patient with symptomatic IART underwent catheter ablation with early success, but IART recurred 1 year later.

Of 10 patients without documented atrial tachyarrhythmia, 3 underwent the surgical conversion procedure because of indications other than rhythm disturbances. The other 7 patients have been free from symptomatic arrhythmia during follow-up.

\section{Conversion to Total Cavopulmonary Connection}

Ten patients underwent the conversion to total cavopulmonary connection with concomitant antiarrhythmic surgery. Major impediments submitted for the conversion included symptomatic atrial tachyarrhythmia in 4 , exercise-induced

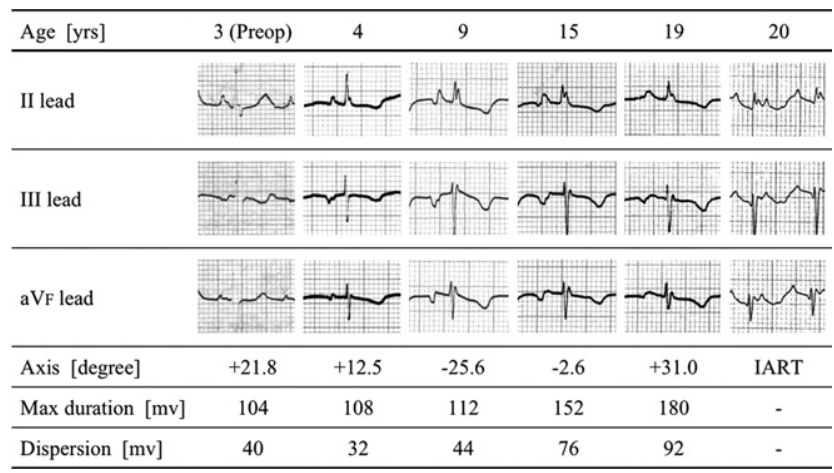

Figure 3. An example of the changes in P-wave characteristics. This patient underwent the initial APC Fontan procedure at the age of 3. Ectopic atrial rhythm developed at the age of 9 years. The maximum $\mathbf{P}$-wave duration and $\mathbf{P}$-wave dispersion became increasingly prolonged, and eventually intra-atrial reentrant tachycardia progressed at the age of 20 years. APC, atriopulmonary connection. 


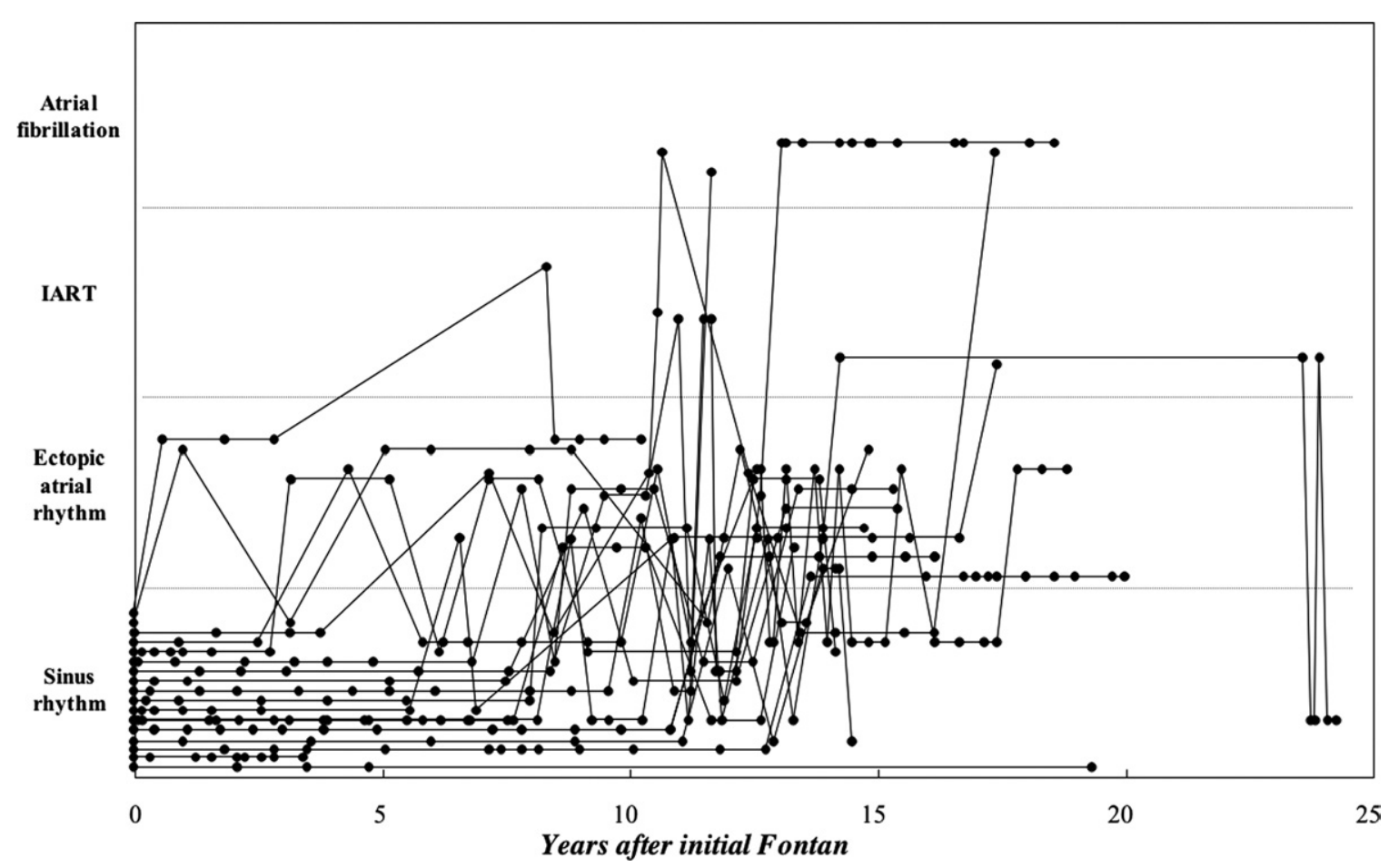

Figure 4. Changes in rhythm. The vertical axis represents the documented rhythm in each electrocardiogram. Ectopic atrial rhythm was common, which preceded the development of intra-atrial reentrant tachycardia (IART) or atrial fibrillation in the majority of cases.

IART in 2, thrombosis in 4 , intracardiac lesions in 2 , and poor exercise tolerance in 1 . The interval between the initial APC Fontan and the conversion procedure ranged from 10.3 to 19.5 years (Table $1 \mathrm{~B}$ ).

As previously described, ${ }^{16}$ an expanded polytetrafluoroethylene tube was inserted intra-atrially in 2 patients undergoing the conversion procedure before 1996 (patients 1 and 3 ). In the other 8 patients, an expanded polytetrafluoroethylene tube was interposed between the inferior caval vein and the pulmonary arteries in an extracardiac fashion. A standard full maze procedure was carried out in 3 patients who had atrial fibrillation, and blocking lines of conduction were created by cryoablation in the other 7 patients.

There was no surgical mortality. The follow-up period after the conversion procedure ranged from 1.0 to 9.8 years. All patients resumed sinus rhythm immediately after the conversion. Eventually, atrial fibrillation recurred and became chronic in 2 patients who had atrial fibrillation and long-term duration of arrhythmia before the conversion (patients 9 and 10). One patient required ventricular pacing owing to symptomatic bradycardia on atrial fibrillation (patient 10). Another patient who preoperatively had atrial fibrillation demonstrated transient IART after the conversion (patient 11). In this patient, a permanent pacemaker was also implanted, because of a transient atrioventricular conduction disturbance 1 month after the conversion. The pacing system has been working just as a backup with stable atrioventricular conduction, and postoperative IART required 32 months' duration of antitachyarrhythmic drug administration. The other 7 patients have been doing well without the need for antiarrhythmic agents or a pacing system after the conversion procedure.

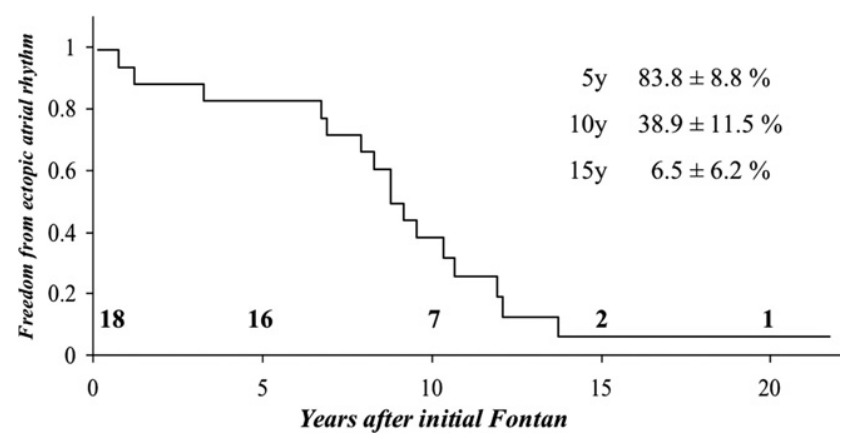

Figure 5. Freedom from ectopic atrial rhythm. The time to ectopic atrial rhythm was defined as the time to the first episode documented by the standard electrocardiogram beyond the immediate postoperative period. Cumulative event-free rate was estimated by the Kaplan-Meier method. 


\section{Discussion}

In various clinical settings with or without structural heart disease, the maximum P-wave duration and the P-wave dispersion, analyzed from the 12-lead surface ECG or signal-averaged ECG, have been regarded as useful markers for the prediction of atrial tachyarrhythmias. ${ }^{23-36}$ Many prior studies have demonstrated that individuals with clinical atrial tachyarrhythmias have significantly longer intraatrial and interatrial conduction time of sinus impulses, which is not only determined by extensive electrophysiologic study but also shown as P-wave prolongation in the 12-lead surface ECG. A prolonged P-wave duration is known to be associated with fragmented and prolonged atrial activation and suggests the presence of arrhythmic re-entry mechanism predisposing to atrial tachyarrhythmias. ${ }^{37,38}$ Similarly, P-wave dispersion during sinus rhythm was found to be significantly greater in patients with atrial tachyarrhythmias; increased $\mathrm{P}$-wave dispersion simply representing nonuniform, anisotropic, and inhomogeneous atrial conduction. ${ }^{24}$

Additionally, recent studies have indicated that the maximum P-wave duration and the P-wave dispersion were prolonged in the Fontan patients with a history of sustained atrial tachyarrhythmias. ${ }^{10,26,31,35,36}$ Both the maximum duration and the dispersion of the $\mathrm{P}$ wave were found to be correlated with the right atrial dimensions. ${ }^{31,35}$ Wong and associates $^{31}$ suggested that mechanical and electrical remodeling of atrial myocardium were interrelated in patients after the Fontan procedure.

In the present study, we performed serial ECG measurements after the APC Fontan procedure and showed that there was a progressive increase in both P-wave duration and dispersion over time. Previous analyses of the P-wave characteristics in the Fontan cohort were based on data at arbitrary time points during the postoperative period. ${ }^{10,26,31,35,36}$ Changes in the P-wave characteristics preceded the onset of symptomatic atrial tachyarrhythmias in our patients. Wong and colleagues ${ }^{31}$ suggested that maximum P-wave duration of $134 \mathrm{~ms}$ or more and P-wave dispersion of $66 \mathrm{~ms}$ or more had a good sensitivity and specificity in identifying the Fontan patients with a history of atrial tachyarrhythmias. Our results are consistent with their finding.

Furthermore, changes in the P-wave axis, which we designated as ectopic atrial rhythm, turned out to be another common phenomenon after the APC Fontan procedure. This most likely reflects sinus nodal dysfunction, real formation of abnormal ectopic foci, or grossly changing geometry of the atrial architecture. $^{21,22}$ Atrial tachyarrhythmias are frequently accompanied by sinus nodal dysfunction, because irregular bradycardia can promote more diversity for refractory period of the atrial muscle and then induce re-entry mechanism. ${ }^{5,21,22}$ Together with the P-wave duration and disper- sion, it is pertinently recommended to pay attention to change or diversity in the P-wave axis.

On the basis of our findings that changes in the P-wave characteristics precede the development of sustained atrial tachycardia, we can revisit a controversial point-that is, the timing for the conversion from the APC Fontan procedure to total cavopulmonary connection. This surgical intervention in association with antiarrhythmic surgery has been reported to be remarkably effective for the treatment of atrial tachyarrhythmias. ${ }^{12-20}$ However, the postoperative status of cardiac rhythm was not always ideal. To restore competent sinus rhythm, we previously recommended that the conversion procedure should be considered within a short time from the initial arrhythmic event, as our early experience suggested that a long duration of atrial tachyarrhythmias was disadvantageous to achieve a successful outcome in this particular respect. ${ }^{16}$ The results of the present study support our previous recommendation with respect to the timing of the conversion. Although it is difficult to determine a precise cutoff line for indication of the conversion surgery, the rhythm prognosis appeared better when used before atrial tachyarrhythmias became sustained. The surgeon does not need to wait until a sustained atrial tachyarrhythmia is recorded. On the basis of the data in Figures 2 and 3, there is no good reason to postpone the conversion surgery in patients with greater values than Wong's criteria (maximum P-wave duration $\geq 134 \mathrm{~ms}$ and P-wave dispersion $\geq 66 \mathrm{~ms}$ ). ${ }^{31}$ Such conditions were much more common 10 years after the initial APC Fontan procedure.

Of course, arrhythmias are not the sole indicators for the conversion procedure. Mechanical obstruction across the systemic or pulmonary venous pathway, elevated cardiac venous pressure, deteriorating functional status, size of the distended atrium, as well as thrombosis, must be taken into account. It is important to recognize that a deteriorating functional status, a grossly dilated right atrium, and thrombosis are often coexistent with arrhythmias. It is also worth considering that, before the onset of clinical atrial tachyarrhythmias, patients are usually free of symptoms and doing quite well. Therefore, it is of vital importance to recognize the ECG changes that precede the onset of atrial tachyarrhythmias. On the basis of the findings from this study, we are actively considering surgical conversion of the remaining 8 patients because a substantial change in terms of the P-wave characteristics has already developed, indicating the presence of a substrate for atrial tachyarrhythmias.

\section{Study Limitations}

The validity of this study is clearly limited by its retrospective nature. We were unable to assess the "true" process of changes in the P-wave characteristics over time because the patients' clinical evaluations were not prospectively 
performed. There was another methodologic difficulty in defining the onset and the offset of the P-wave manually, which may restrict the accuracy and the reproducibility of the measurements. ${ }^{39}$ However, this method was performed and accepted previously by other investigators. ${ }^{24-34}$

\section{Conclusions}

The maximum P-wave duration and the P-wave dispersion progressively increased over time after the conventional APC Fontan procedure in conjunction with an increase in frequency of ectopic atrial rhythms. These P-wave changes were regarded as a precursor of atrial tachyarrhythmias and were helpful in timing the conversion from the APC Fontan procedure to total cavopulmonary connection, so that surgical conversion could be arranged preferably before sustained atrial tachyarrhythmias ensue.

We express our special thanks to Ms Akiko Kada, MPH, who kindly gave us suggestions to conduct the statistical analysis.

\section{References}

1. Peters NS, Somerville J. Arrhythmias after the Fontan procedure. $\mathrm{Br}$ Heart J. 1992;68:199-204.

2. Balaji S, Johnson TB, Sade RM, Case CL, Gillette PC. Management of atrial flutter after the Fontan procedure. J Am Coll Cardiol. 1994;23: 1209-15.

3. Ghai A, Harris L, Harrison DA, Webb GD, Siu SC. Outcomes of late atrial tachyarrhythmias in adults after the Fontan operation. J Am Coll Cardiol. 2001;37:585-92.

4. Fishberger SB, Wernovsky G, Gentles TL, Gauvreau K, Burnett J, Mayer JE Jr, et al. Factors that influence the development of atrial flutter after the Fontan operation. J Thorac Cardiovasc Surg. 1997; 113:80-6.

5. Kurer CC, Tanner CS, Vetter VL. Electrophysiologic findings after Fontan repair of functional single ventricle. J Am Coll Cardiol. 1991; 17:174-81.

6. Gewillig M, Wyse RK, de Leval MR, Deanfield JE. Early and late arrhythmias after the Fontan operation: predisposing factors and clinical consequences. Br Heart J. 1992;67:72-9.

7. Balaji S, Gewillig M, Bull C, de Leval MR, Deanfield JE. Arrhythmias after the Fontan procedure. Comparison of total cavopulmonary connection and atriopulmonary connection. Circulation. 1991;84(5 Suppl): III162-7.

8. Gelatt M, Hamilton RM, McCrindle BW, Gow RM, Williams WG, Trusler GA, et al. Risk factors for atrial tachyarrhythmias after the Fontan operation. J Am Coll Cardiol. 1994;24:1735-41.

9. Cecchin F, Johnsrude CL, Perry JC, Friedman RA. Effect of age and surgical technique on symptomatic arrhythmias after the Fontan procedure. Am J Cardiol. 1995;76:386-91.

10. Weber HS, Hellenbrand WE, Kleinman CS, Perlmutter RA, Rosenfeld LE. Predictors of rhythm disturbances and subsequent morbidity after the Fontan operation. Am J Cardiol. 1989;64:762-7.

11. Durongpisitkul K, Porter CJ, Cetta F, Offord KP, Slezak JM, Puga FJ, et al. Predictors of early- and late-onset supraventricular tachyarrhythmias after Fontan operation. Circulation. 1998;98:1099-107.

12. Mavroudis C, Backer CL, Deal BJ, Johnsrude CL. Fontan conversion to cavopulmonary connection and arrhythmia circuit cryoblation. J Thorac Cardiovasc Surg. 1998;115:547-56.

13. Deal BJ, Mavroudis C, Backer CL, Johnsrude CL, Rocchini AP. Impact of arrhythmia circuit cryoablation during Fontan conversion for refractory atrial tachycardia. Am J Cardiol. 1999;83:563-8.

14. Nomura F, Finucane K, Smith W, Kerr AR. The failing Fontan with atrial flutter: a successful surgical option. Ann Thorac Surg. 1999;68: 1845-8.
15. Marcelletti CF, Hanley FL, Mavroudis C, McElhinney DB, Abella RF, Marianeschi SM, et al. Revision of previous Fontan connections to total extracardiac cavopulmonary anastomosis: a multicenter experience. J Thorac Cardiovasc Surg. 2000;119:340-6.

16. Kawahira Y, Uemura H, Yagihara T, Yoshikawa Y, Kitamura S. Renewal of the Fontan circulation with concomitant surgical intervention for atrial arrhythmia. Ann Thorac Surg. 2001;71:919-21.

17. Mavroudis C, Backer CL, Deal BJ, Johnsrude C, Strasburger J. Total cavopulmonary conversion and maze procedure for patients with failure of the Fontan operation. J Thorac Cardiovasc Surg. 2001; 122:863-71.

18. Deal BJ, Mavroudis C, Backer CL, Buck SH, Johnsrude C. Comparison of anatomic isthmus block with the modified right atrial maze procedure for late atrial tachycardia in Fontan patients. Circulation. 2002;106:575-9.

19. Setty SP, Finucane K, Skinner JR, Kerr AR. Extracardiac conduit with a limited maze procedure for the failing Fontan with atrial tachycardias. Ann Thorac Surg. 2002;74:1992-7.

20. Vignati G, Crupi G, Vanini V, Iorio FS, Borghi A, Giusti S. Surgical treatment of arrhythmias related to congenital heart diseases. Ann Thorac Surg. 2003;75:1194-9.

21. Manning PB, Mayer JE Jr, Wernovsky G, Fishberger SB, Walsh EP. Staged operation to Fontan increases the incidence of sinoatrial node dysfunction. J Thorac Cardiovasc Surg. 1996;111:833-40.

22. Cohen MI, Wernovsky G, Vetter VL, Wieand TS, Gaynor JW, Jacobs ML, et al. Sinus node function after a systematically staged Fontan procedure. Circulation. 1998;98(19 Suppl):II352-9.

23. Buxton AE, Josephson ME. The role of $\mathrm{P}$ wave duration as a predictor of postoperative atrial arrhythmias. Chest. 1981;80:68-73.

24. Dilaveris PE, Gialafos EJ, Sideris SK, Theopistou AM, Andrikopoulos GK, Kyriakidis M, et al. Simple electrocardiographic markers for the prediction of paroxysmal idiopathic atrial fibrillation. Am Heart J. 1998;135:733-8.

25. Chang CM, Lee SH, Lu MJ, Lin CH, Chao HH, Cheng JJ, et al. The role of $\mathrm{P}$ wave in prediction of atrial fibrillation after coronary artery surgery. Int J Cardiol. 1999;68:303-8.

26. Li W, Xiao HB, Henein MY, Somerville J, Gibson DG. Progressive ECG changes before the onset of atrial flutter in adult congenital heart disease patients. Heart. 2001;85:703.

27. Ho TF, Chia EL, Yip WC, Chan KY. Analysis of $\mathrm{P}$ wave and $\mathrm{P}$ dispersion in children with secundum atrial septal defect. Ann Noninvasive Electrocardiol. 2001;6:305-9.

28. Guray U, Guray Y, Yylmaz MB, Mecit B, Sasmaz H, Korknaz S, et al. Evaluation of $\mathrm{P}$ wave duration and $\mathrm{P}$ wave dispersion in adult patients with secundum atrial septal defect during normal sinus rhythm. Int J Cardiol. 2003;91:75-9.

29. Dogan A, Acar G, Gedikli O, Ozaydin M, Nazli C, Altinbas A, et al. A comparison of P-wave duration and dispersion in patients with short-term and long-term atrial fibrillation. J Electrocardiol. 2003;36: 251-5.

30. Altunkeser BB, Ozdemir K, Gok H, Temizhan A, Tokac M, Karabag T. Can P wave parameters obtained from 12-lead surface ECG be a predictor for atrial fibrillation in patients who have structural heart disease? Angiology. 2003;54:475-9.

31. Wong T, Davlouros PA, Li W, Millington-Sanders C, Francis DP, Gatzoulis MA. Mechano-electrical interaction late after Fontan operation: relation between P-wave duration and dispersion, right atrial size, and atrial arrhythmias. Circulation. 2004;109:2319-25.

32. Guray U, Guray Y, Mecit B, Yilmaz MB, Sasmaz H, Korkmaz S. Maximum $\mathrm{p}$ wave duration and $\mathrm{p}$ wave dispersion in adult patients with secundum atrial septal defect: the impact of surgical repair. Ann Noninvasive Electrocardiol. 2004;9:136-41.

33. Dogan A, Avsar A, Ozturk M. P-wave dispersion for predicting maintenance of sinus rhythm after cardioversion of atrial fibrillation. Am J Cardiol. 2004;93:368-71.

34. Hallioglu O, Aytemir K, Celiker A. The significance of $P$ wave duration and $\mathrm{P}$ wave dispersion for risk assessment of atrial tachyarrhythmias in patients with corrected tetralogy of Fallot. Ann Noninvasive Electrocardiol. 2004;9:339-44. 
35. Inamura N, Matsushita T, Fukunami M, Sano T, Takeuchi M, Kurotobi $\mathrm{S}$, et al. $\mathrm{P}$ wave signal averaged electrocardiography in patients undergoing the Fontan operation. J Cardiol. 2002;39:101-7.

36. Tuzcu V, Ozkan B, Sullivan N, Karpawich P, Epstein ML. P wave signal-averaged electrocardiogram as a new marker for atrial tachyarrhythmias in postoperative Fontan patients. J Am Coll Cardiol. 2000; 36:602-7.

37. Watson RM, Josephson ME. Atrial flutter. I. Electrophysiologic substrates and modes of initiation and termination. Am J Cardiol. 1980; 45:732-41.

38. Tanigawa M, Fukatani M, Konoe A, Isomoto S, Kadena M, Hashiba $\mathrm{K}$. Prolonged and fractionated right atrial electrograms during sinus rhythm in patients with paroxysmal atrial fibrillation and sick sinus node syndrome. J Am Coll Cardiol. 1991;17:403-8.

39. Dilaveris PE, Gialafos JE. P-wave duration and dispersion analysis: methodological considerations. Circulation. 2001;103:E111-1.

\section{Discussion}

Dr Constantine Mavroudis (Chicago, Ill). Dr Koh, you have performed a retrospective study in a relatively small group of patients in whom you noted time-related changes of P-wave characteristics that result in a stepwise degeneration of coordinated atrial activity leading to ectopic atrial arrhythmias, atrial tachycardia, and eventually atrial fibrillation in APC Fontan patients with tricuspid atresia. This is a relatively small group of patients with one diagnosis.

You developed a thesis that atriopulmonary to total cavopulmonary artery extracardiac Fontan conversion should be performed on the basis of $\mathrm{P}$-wave abnormalities even before atrial tachycardia and symptoms cause complications in existing patients with a stable APC Fontan.

The idea that all APC Fontan patients regardless of symptoms or abnormal hemodynamic findings should be converted to total cavopulmonary extracardiac connections has been proposed at a very recent 2005 World Congress in Buenos Aires. The present paper by you and your associates has refined this thesis with objective data based on P-wave morphology.

Dr Koh, since increasing right atrial size is a marker for arrhythmias, did you correlate increasing right atrial size with the onset of arrhythmias? In other words, could you determine the percentage of increase in right atrial size that correlated with the onset of atrial arrhythmias and changes of the P-wave morphology?

You selected as your study group patients with tricuspid atresia. This makes sense because we have the most follow-up with these patients; they seem to have done better 20 years ago. However, do you have any experience with other single ventricle patients, perhaps with heterotaxy syndrome or other complex anatomy?
In closing, I want to emphasize the progressive indications for Fontan patients in our population of 100 patients at Children's Memorial Hospital in Chicago. Initially, we were very hesitant to operate primarily for atrial arrhythmias, insisting on more basic indications such as pathway obstruction and valvular abnormalities. We have since eased our indications to one or more of the following: atrial arrhythmias, pathway obstructions, valvular dysfunction, decreased ventricular function when it is arrhythmiarelated, and decreased functional status. We have not embraced the idea of operating without findings, and we have not developed reliable predictive indications in asymptomatic patients.

You have challenged us to adjust our indications with predictive indications such as your P-wave morphology study. More studies with more patients will be necessary to delineate further this very interesting idea.

Dr Koh. To answer your first question, we did not measure the size of the right atrium in this study; however, several other investigators showed correlation between the P-wave duration and size of the right atrium. I referred to the study of Dr Wong in this presentation. He called this relationship "mechano-electorical interaction." $\mathrm{He}$ and his colleagues showed that $\mathrm{P}$-wave duration is correlated with size of the right atrium measured with echocardiography.

Dr Mavroudis. Do you have any experience with other types of anatomy, other substrates, for example, heterotaxy syndrome?

Dr Koh. To homogenize morphologic background, we selected patients with simple tricuspid atresia as the study population. We believe that cardiac morphology influences the P-wave characteristics. In the preliminary study, we assessed changes of the P-wave characteristics in a small number of heterotaxy patients. In the heterotaxy patients, changes of the P-wave axis were frequent, probably resulting from variable location of the conduction system. Therefore, we found it difficult to show time-related changes in the P-wave characteristics in this particular group.

Dr Mavroudis. It is safe to conclude, then, that the findings that you have here are specific for patients with tricuspid atresia, and for any other patients it remains to be seen what the results of P-wave morphology will be over time. Is that correct?

Dr Koh. Yes. The main message of this study is that APC Fontan patients eventually have rhythm disturbance and early conversion is justifiable. I believe this phenomenon is universal in any setting, although it is difficult to show it in terms of the P-wave characteristics. 